\title{
DESEMPENHO PRODUTIVO DE VACAS HOLANDESAS EM PASTAGEM DE MILHETO E FEIJÃO MIÚDO COM E SEM SUPLEMENTAÇÃO
}

\section{PRODUCTIVE PERFORMANCE OF HOLSTEIN COWS IN A MIXED PASTURE OF PEARL MILLET AND COWPEA WITH AND WITHOUD SUPLEMENTATION}

\author{
Ana Lúcia HANISCH ${ }^{1}$ \\ Marcelo ABREU DA SILVA ${ }^{2}$ \\ Renato Borges de MEDEIROS ${ }^{3}$
}

\begin{abstract}
RESUMO
Foi avaliado o desempenho produtivo de vacas da raça Holandesa mantidas em pastagem consorciada de milheto (Pennisetum glaucum (L.) R. Brown) e feijão miúdo (Vigna unguiculata L.), recebendo ou não suplementação diária, durante o período de 18/12/2000 a 20/02/2001. Foram utilizadas 12 vacas multíparas, selecionadas pelo potencial produtivo, peso vivo e fase de lactação. Após estratificação, os animais foram distribuídos aleatoriamente em dois grupos que foram manejados em dois sistemas alimentares: pastagem consorciada de milheto e feijão miúdo à vontade (MFM); e pastagem consorciada à vontade + suplementação diária (MFM+S). Utilizou-se delineamento experimental inteiramente casualizado. A disponibilidade de matéria seca (MS) da forragem foi, em média, de $2.469,6$ e 1.554,8 $\mathrm{kg} \mathrm{ha}^{-1}$, respectivamente, na entrada e na saída dos animais dos piquetes. $\mathrm{O}$ valor nutritivo do pasto apresentou valores médios de $70,25 \mathrm{dag} \mathrm{kg}^{-1}$ de digestibilidade in vitro da matéria orgânica; 16,5 dag kg ${ }^{-1}$ de proteína bruta e $68,5 \mathrm{dag} \mathrm{kg}^{-1}$ de fibra detergente neutro. $\mathrm{O}$ feijão miúdo apresentou participação média de $12 \%$ na composição total do pasto. Houve diferença significativa $(P<0,01)$ na produção de leite entre as vacas mantidas nos dois sistemas alimentares, sendo a produção média de leite de 19,56 e 23,40 kg vaca ${ }^{-1} \mathrm{dia}^{-1}$, respectivamente, no sistema MFM e MFM+S. A produção de leite dos animais que receberam suplementação foi mais estável entre os períodos de avaliação.

Palavras-chave: disponibilidade de forragem; pastejo; consorciação; produção de leite.
\end{abstract}

\begin{abstract}
Holstein cows milk production were evaluated under two grazing management systems: a mixed pasture of pearl millet (Pennisetum glaucum (L.) R. Brown) and cowpea (Vigna unguiculata L.) with or without supplementation to the animals, during the period of 18/12/2000 a 20/02/2001. Twelve multipara cows of the Holstein breed were used. They were selected by their production potential, live weight (LW) and lactation period. After the stratification, the animals were randomly distributed between the two treatment groups of the experiment: animals kept under grazing in a mixed pasture of pearl millet and cowpea; and animals kept in the same pasture receiving supplementation in a daily basis. The experiment was carried out in a completely randomized design. The average dry matter was $2469 \mathrm{~kg} \mathrm{ha}^{-1}$ at the entrance and $1554 \mathrm{~kg} \mathrm{ha}^{-1}$ at the animal exit from the enclosed pasture. The harvest pasture dry matter presented $16.5 \mathrm{dag} \mathrm{kg}^{-1}$ of crude protein, $68.5 \mathrm{dag} \mathrm{kg}^{-1}$ of neutral detergent fiber and $70.25 \mathrm{dag} \mathrm{kg}^{-1}$ of digestibility in vitro of organic matter. The average participation of Cowpea in the mixture pasture was $12 \%$. There was a significant difference in milk production of milk between the two grazing systems treatments. The average milk productions were $19.56 \mathrm{~kg}_{\text {day }}^{-1}$ to cows receiving only pasture and $23.40 \mathrm{~kg}$ day $^{-1}$ to the ones supplemented. The supplementation promoted more stability in cow milk production between the evaluation periods.

Key-words: forage availability; grazing; mixed pasture; milk production.
\end{abstract}

\footnotetext{
${ }^{1}$ Enga agrônoma, M.Sc. Pesquisadora - Epagri - Estação Experimental de Canoinhas - Caixa Postal 216, CEP 89460-000, Canoinhas, SC, Brasil. E-mail: analucia@epagri.sc.gov.br

2 Professor, Dr., Departamento de Plantas Forrageiras e Agrometereologia, Universidade Federal do Rio Grande do Sul, Porto Alegre, RS, Brasil. E-mail: masabreu@ufrgs.br

${ }_{3}$ Professor, Dr., Departamento de Plantas Forrageiras e Agrometereologia, Universidade Federal do Rio Grande do Sul, Porto Alegre, RS, Brasil. E-mail: renato.medeiros@ufrgs.br
} 


\section{INTRODUÇÃO}

A pecuária leiteira no Brasil caracteriza-se por grande heterogeneidade dos sistemas de produção, o que contribui para a baixa produtividade média nacional, de $5,7 \mathrm{~kg}$ vaca $^{-1} \mathrm{dia}^{-1}$ (Anualpec, 2005). No entanto, o potencial de produção de leite é muito grande devido às condições climáticas de temperatura e precipitação favoráveis do país, sobretudo nos sistemas de produção com base em pastagens. Nas principais regiões produtoras de leite do Brasil, nota-se aumento na implantação de sistemas intensivos de produção de leite em pastagens, buscando maior eficiência no uso de insumos e recursos forrageiros (Deresz et al., 2006).

Essa tendência de intensificação tem alcançado recentes avanços nas mais variadas regiões do mundo e diversos trabalhos (Kolver \& Muller, 1998; Peyraud et al., 2001; Ribeiro Filho et al., 2007) indicam possibilidades de incremento sobre a produtividade e de redução de custos, por meio da utilização de pastagens de qualidade, particularmente com vacas de alto potencial genético.

O uso de pastagens adaptadas regionalmente e bem manejadas é uma ferramenta eficiente para diferentes sistemas de produção. Em sistemas extensivos, com o uso de animais de produção moderada, um programa de alimentação à base de pastagens diversificadas, tende a minimizar a estacionalidade e aumentar a produção por animal e por área. Favoreto et al. (2008) avaliando a produção de vacas mestiças Holandês $x$ Zebu, em pastagens de grama estrela (Cynodon nlemfuensis Vanderyst) cv. Africana, obtiveram produções de leite de $11,7 \mathrm{~kg} \mathrm{vaca}{ }^{-1} \mathrm{dia}^{-1} \mathrm{com}$ suplementação diária de $2 \mathrm{~kg}$ de concentrado. Com capim-elefante (Pennisetum purpureum Shum.) cv. Napier, Deresz et al. (2006) obtiveram média de $11,65 \mathrm{~kg} \mathrm{vaca}^{-1} \mathrm{dia}^{-1}$ em pastejo rotativo, durante 120 dias de avaliação.

Por outro lado, em sistemas produtivos com maior intensificação tecnológica e com animais de maior potencial genético, a utilização de pastagens de alta qualidade pode reduzir os custos de alimentação e aumentar a renda dos produtores. $\mathrm{O}$ uso de gramíneas de estação quente, como o milheto tem função assegurada em sistemas de pastejo que visem alta produtividade de forragem e animal por área (Martins et al., 2005). Assim, pode levar a estimular a manutenção de altas produções, contribuir para a saúde dos animais em produção, bem como reduzir os impactos ambientais característicos de sistemas mais intensivos.

Uma estratégia para aumentar os índices de produtividade animal em sistemas com base em pastagens cultivadas é o uso de consorciações, especialmente com a inclusão de leguminosas. As leguminosas forrageiras, em face da capacidade de fixação simbiótica do nitrogênio atmosférico e a sua contribuição para a produção animal, são essenciais para incrementar a produtividade e constituem um caminho na direção da sustentabilidade dos sistemas agropecuários (Barcellos et al., 2008) No entanto, existe um número ainda reduzido de pesquisas no Brasil para avaliar a produtividade de vacas de leite em pastejo com 0 uso de pastagens consorciadas de gramíneas e leguminosas, especialmente, com espécies tropicais. Dessa forma, o objetivo deste trabalho foi avaliar a produtividade e a qualidade de pastos consorciados de milheto e feijão miúdo e seus efeitos na produção de vacas leiteiras de alto potencial genético, com e sem suplementação da dieta.

\section{MATERIAL E MÉTODOS}

O presente trabalho foi conduzido entre os meses de dezembro de 2000 e fevereiro de 2001 na Granja VB, no município de Eldorado do Sul, Estado do Rio Grande do Sul, situada a uma altitude de $46 \mathrm{~m}, 30^{\circ} 05^{\prime}$ de latitude Sul, $51^{\circ} 40^{\prime}$ de longitude Oeste e clima do tipo subtropical úmido $\mathrm{Cfa}$, segundo a classificação de Köeppen. As pastagens de milheto (Pennisetum glaucum (L.) R. Brown) e feijão miúdo (Vigna unguiculata L.) foram semeadas na área experimental, utilizando-se $30 \mathrm{~kg}$ $\mathrm{ha}^{-1}$ de sementes de milheto e $15 \mathrm{~kg} \mathrm{ha}^{-1}$ de feijão miúdo. A semeadura a lanço das espécies foi realizada após preparo mínimo da área, com subsolagem sobre resteva de azevém. Aplicou-se $100 \mathrm{~kg} \mathrm{ha}^{-1}$ da fórmula $\mathrm{N}-\mathrm{P}_{2} \mathrm{O}_{5}-\mathrm{K}_{2} \mathrm{O} 5-20-20$ e 150 $\mathrm{kg}$ de $\mathrm{N}$ na forma de uréia, parcelados em quatro aplicações (CQFS, 1995). O primeiro pastejo nos piquetes ocorreu em torno de 45 dias após a semeadura.

Foram utilizadas 12 vacas da raça Holandesa, multíparas, com alta homogeneidade genética, selecionadas no rebanho da propriedade em função do potencial produtivo $\left(31,26 \pm 3,3 \mathrm{~kg}\right.$ de leite $\left.\mathrm{dia}^{-1}\right)$, da massa viva $(576 \pm 54,20 \mathrm{~kg})$ e dos dias de lactação (128 \pm 46,5). Após a estratificação, realizada com base nestes três fatores, os animais foram divididos, ao acaso, em dois grupos de seis animais e destinados de forma aleatória aos dois sistemas de manejo avaliados: fornecimento à vontade de pasto consorciado de milheto e feijão miúdo, sem suplementação (MFM); mesmo pasto à vontade + suplementação diária $(M F M+S)$. O manejo MFM+S reproduzia o modelo tecnológico adotado pela propriedade, de forma que as seis vacas selecionadas foram marcadas e reunidas novamente ao rebanho de vacas em lactação. A suplementação diária foi composta pelos seguintes ingredientes: $3 \mathrm{~kg}$ de concentrado (24 dag $\mathrm{kg}^{-1} \mathrm{de}$ proteína bruta, 2 dag $\mathrm{kg}^{-1}$ de extrato etéreo, 13 dag $\mathrm{kg}^{-1}$ de matéria fibrosa; 10 dag $\mathrm{kg}^{-1}$ de matéria mineral, 5 dag $\mathrm{kg}^{-1}$ de cálcio e 0,6 dag $\mathrm{kg}^{-1}$ de fósforo $)+2 \mathrm{~kg}$ de casca de soja $\left(88,24 \mathrm{dag} \mathrm{kg}^{-1}\right.$ de matéria seca) $+15 \mathrm{~kg}$ de planta inteira de milho picada $\left(30,67\right.$ dag $\mathrm{kg}^{-1}$ de $\left.\mathrm{MS}\right)$. O milho foi substituído no terceiro período de avaliação, por 24 $\mathrm{kg}$ de resíduo de cervejaria (24,3 dag $\mathrm{kg}^{-1}$ de $\mathrm{MS}$ ), devido à necessidade dos proprietários em aproveitarem um volumoso de alta disponibilidade e baixo custo, na ocasião. 
HANISCH, A.L., et al. Desempenho produtivo de vacas...

As vacas selecionadas destinadas ao MFM foram adaptadas à condição de não serem suplementadas durante sete dias antes do início do experimento. Todas as vacas foram ordenhadas diariamente às $06 \mathrm{~h} 00 \mathrm{~min}$ e às $17 \mathrm{~h} 30 \mathrm{~min}$ e faziam um trajeto médio diário de $500 \mathrm{~m}$ entre os piquetes e a ordenha. Os animais permaneciam em áreas de pasto, com acesso à sombra, água e sal mineral. A produção individual de leite foi medida através de controle leiteiro, realizado a cada 14 dias, durante a ordenha da manhã e a da tarde, com a utilização de um medidor por amostragem. Os animais foram pesados no início, 15 dias após e no final do experimento.

As vacas destinadas ao sistema pastagem mais suplementação (MFM+S) acompanhavam as demais vacas do rebanho da propriedade para as áreas de pasto, em sistema rotativo, em piquetes com um dia de ocupação e 15 a 18 dias de descanso. Os piquetes constituíram as unidades experimentais onde foram realizadas as avaliações de disponibilidade de forragem para este sistema de manejo.

Em função da ocorrência de altas temperaturas no período de avaliação e da distribuição irregular de sombra na propriedade foi adotado um procedimento especial para as vacas destinadas ao sistema MFM: para esse tratamento foi utilizada uma área total de 5 ha, com a mesma pastagem de milheto e feijão miúdo, sendo que 2 ha foram mantidos em sistema de lotação contínua, durante todo o período do experimento, nos horários compreendidos entre a ordenha da manhã e a ordenha da tarde, a fim de permitir que as mesmas tivessem acesso à sombra. Após a ordenha da tarde as vacas eram levadas para a área de 3 ha, dividida em 8 piquetes, sendo que cada piquete constituía uma unidade experimental. Esses piquetes foram divididos com cercas eletrificadas, com períodos de ocupação de duas noites e 15 dias de descanso. Na área de pastejo diurno, o manejo da pastagem foi realizado de modo a permitir um resíduo mínimo de $1.000 \mathrm{~kg}$ ha 1 de MS de forragem, enquanto nos piquetes noturnos procurou-se manter as disponibilidades de forragem em, aproximadamente, 2.000 e $1.000 \mathrm{~kg}$ $\mathrm{ha}^{-1}$ de MS, respectivamente, na entrada e na saída dos animais de cada piquete. No sistema rotativo foi realizada uma roçada após o segundo pastejo em cada piquete.

As determinações da disponibilidade de forragem em cada período foram realizadas a cada 14 dias $(03 / 01 ; 17 / 01 ; 31 / 01$ e 15/02), através do Método de Dupla Amostragem, usando-se estimativa visual e cortes (Haydock \& Shaw, 1975). A determinação da disponibilidade de forragem no início e no final de cada período de utilização foi realizada utilizando-se 20 amostras cortadas, com tesoura de tosquia ao nível do solo e 60 observações visuais. As 20 amostras cortadas eram pesadas e dessas, cinco amostras eram levadas para secagem em estufa de circulação forçada de ar a $65^{\circ} \mathrm{C}$, por $72 \mathrm{~h}$, para determinação do teor de matéria seca (MS) e, posteriormente, moídas e encaminhadas para análise bromatológica para determinação do teor de proteína bruta (PB), pelo método Kjeldahl (AOAC, 1984); fibra detergente neutro (FDN), pelo método de Van Soest et al. (1991) e digestibilidade in vitro (DIVMO) pela técnica e Tilley \& Terry (1963).

Para a determinação da composição estrutural do pasto, utilizou-se $30 \%$ do total das amostras cortadas para avaliação da disponibilidade de MS. As amostras eram pesadas e separadas nos componentes: matéria morta, feijão miúdo, outras espécies e milheto e, este por sua vez, em lâminas, bainhas e colmos.

$\mathrm{O}$ valor nutritivo da dieta consumida para o sistema MFM foi estimado, através do cálculo da média dos valores de FDN, PB e DIVMO, obtidos de cada componente, na entrada dos animais nos piquetes, ponderada em função das quantidades consumidas de cada um destes componentes. Por sua vez, a composição nutricional da dieta do sistema MFM+S foi obtida a partir da média dos teores de FDN, PB e DIVMO da forragem ingerida e dos ingredientes utilizados na suplementação, ponderada em função do consumo estimado. $\mathrm{Na}$ análise da composição bromatológica do suplemento foram obtidas duas amostras compostas, a partir da coleta de cada componente em dois períodos diferentes, devido à alteração da dieta com a introdução do resíduo de cervejaria na terceira data de avaliação.

O delineamento experimental utilizado foi o inteiramente casualizado, sendo que os valores médios das variáveis avaliadas do pasto por repetição (piquete) constituíram as unidades amostrais analisadas por período. As análises estatísticas utilizaram a rotina de testes de aleatorização do programa MULTIV (Pillar, 1997) em nível de $1 \%$ de probabilidade de erro.

\section{RESULTADOS E DISCUSSÃO}

Houve diferenças significativas $(P<0,01)$ entre as médias de produção de leite obtidas nas vacas mantidas nos dois sistemas de produção (Tabela 1), sendo maior a produtividade alcançada pelas vacas no sistema pastagem mais suplementação $\left(23,40 \mathrm{~kg}\right.$ vaca $\left.^{-1} \mathrm{dia}^{-1}\right)$ em relação às vacas no sistema somente pastagem $(19,56 \mathrm{~kg}$ $\left.v \operatorname{vca}^{-1} \mathrm{dia}^{-1}\right)$. Houve diferença também na produção de leite durante as datas de avaliação dentro de cada sistema de manejo. No sistema MFM houve redução da produção de leite de forma gradativa entre os quatro períodos. A produção de $24,42 \mathrm{~kg}$ vaca $^{-1} \mathrm{dia}^{-1}$ registrada no primeiro período caiu para $15,08 \mathrm{~kg}$ vaca $^{-1} \mathrm{dia}^{-1}$ no último período, representando uma redução de $38,3 \%$. No sistema com suplementação não houve diferença na produção de leite durante os três primeiros períodos de avaliação, indicando que o sistema apresentou um efeito estabilizador da produção. No primeiro período registrou-se $26,08 \mathrm{~kg}$ vaca $^{-1} \mathrm{dia}^{-1}$ e no terceiro $22,58 \mathrm{~kg} \mathrm{vaca}^{-1} \mathrm{dia}^{-1}$ o que resultou em uma queda de apenas 13,4\%. Este efeito estabilizador é de grande importância para os produtores que 
HANISCH, A.L., et al. Desempenho produtivo de vacas...

optam por este tipo de sistema, uma vez que um pasto com valor nutritivo adequado, associada à uma suplementação acessível e de baixo custo, pode contribuir para reduzir as oscilações na produção de leite ao longo das estações do ano.

TABELA 1 - Médias diárias de produção de leite de vacas conduzidas em dois sistemas de manejo: somente sob pastejo de milheto e feijão miúdo (MFM) e pastejo mais suplementação (MFM+S)

\begin{tabular}{cccccc}
\hline \multicolumn{5}{c}{${\text { Produção de leite }-\mathrm{kg} \mathrm{vaca}^{-1} \mathrm{dia}^{-1}}^{c}$ Datas } \\
\hline \multirow{2}{*}{ Tratamentos } & $03 / 01 / 2001$ & $17 / 01 / 2001$ & $31 / 01 / 2001$ & $14 / 02 / 2001$ & Média \\
\cline { 2 - 6 } & $24,42 \mathrm{~A}$ & $19,75 \mathrm{~B}$ & $19 \mathrm{~B}$ & $15,08 \mathrm{C}$ & $19,56 \mathrm{~b}$ \\
MFM & $26,08 \mathrm{~A}$ & $25,42 \mathrm{~A}$ & $22,58 \mathrm{~A}$ & $20,33 \mathrm{~B}$ & $23,40 \mathrm{a}$ \\
\hline
\end{tabular}

Médias seguidas de mesma letra, minúscula nas colunas e maiúsculas nas linhas, não diferem entre, si pelo teste de aleatorização, em nível de $1 \%$ de probabilidade de erro.

Durante o mês de janeiro, as vacas recebendo somente pasto de milheto e feijão miúdo, mantiveram

média de produção individual acima de $19 \mathrm{~kg}$ vaca $1 \mathrm{dia}^{-1}$. Vilela et al. (2006) avaliaram vacas Holandesas em pastagem de coastcross e obtiveram médias de 15,5 e 19,1 $\mathrm{kg}$ vaca $^{-1} \mathrm{dia}^{-1} \mathrm{com}$ 3 e $6 \mathrm{~kg}$ de concentrado, respectivamente e sugerem que para a obtenção de produções de leite acima de $15 \mathrm{~kg}$ vaca $^{-1}$ dia $^{-1}$, nos animais de alto potencial, é necessário suplementar a dieta com concentrado.

Em geral, esse nível de produção de leite individual, tem sido obtido com vacas mantidas em pastagens compostas predominantemente por espécies de clima temperado. Delagarde et al. (1997) registraram produções médias de $22,7 \mathrm{~kg}$ vaca $^{-1} \mathrm{dia}^{-1}$, em pastejo de azevém perene, por um período de dois meses, sem suplementação, controlando a oferta de matéria seca de forragem em $20 \mathrm{~kg} \mathrm{vaca}^{-1} \mathrm{dia}^{-1}$. Ribeiro Filho et al. (2009) fornecendo pastagem de azevém anual para vacas da mesma raça, obtiveram produção de leite de 18,4 e $21,1 \mathrm{~kg} \mathrm{dia}^{-1}$ nas ofertas de 25 e $40 \mathrm{~kg}$ vaca $^{-1}$ $\mathrm{dia}^{-1}$ de MS, respectivamente.

Nascimento Jr. et al. (2003) consideram que é possível a comparação de forrageiras tropicais com as de clima temperado quando estas forem manejadas de forma que sejam oferecidas aos animais nos primeiros estágios de crescimento. Com base nesta premissa, pode-se inferir que, no presente trabalho, a oferta de forragem de uma pastagem tropical consorciada como de milheto + feijão miúdo no estádio de desenvolvimento fenológico inicial, permite ao animal colher uma dieta com potencial de produção de leite semelhantes aos obtidos em pastagens de clima temperado como as descritas por Delagarde et al. (1997) e Ribeiro Filho et al. (2009).

Os valores médios de disponibilidade de forragem foram de $2.469,6$ e $1.554,8 \mathrm{~kg} \mathrm{ha}^{-1}$ de MS respectivamente, na entrada e na saída dos animais dos piquetes propiciando, uma oferta de matéria seca e de lâminas foliares de milheto não limitantes ao consumo (Holmes \& Wilson, 1989), durante todo o período de realização do experimento (Tabela 2). A composição estrutural do milheto durante 0 experimento permitiu aos animais a seletividade da dieta, como pode ser vista na partição da MS do milheto na entrada e na saída dos animais nos piquetes (Tabela 3 ).

A prática da roçada após o segundo pastejo nos piquetes contribuiu para a manutenção de uma alta porcentagem média de folhas de milheto (65\%) em relação ao total da matéria seca registrada, uma vez que não ocorreram diferenças significativas $(P>0,01)$ na disponibilidade relativa de folhas nos quatro períodos de avaliação no pastejo rotativo e nos três primeiros períodos do pastejo contínuo (Tabela 2). No pastejo contínuo, onde não ocorreu a prática da roçada, as aplicações de $\mathrm{N}$ não foram suficientes para retardar 0 desenvolvimento fenológico do milheto, que apresentou redução na proporção de lâminas no último período de observação (Tabela 2), coincidindo com o final de seu ciclo e com o estágio em que ocorreu a queda mais acentuada na produção de leite.

Associado à redução na disponibilidade de folhas verdes no último período no pastejo contínuo, houve também redução no teor de proteína bruta (PB) na última avaliação (Tabela 4). Nas demais datas de avaliação da composição bromatológica do pasto, os resultados aproximam-se dos obtidos por Santos et al. (2005), que avaliaram o desempenho animal em pastagens de milheto, obtiveram 17,2 dag kg-1 de PB e 60,2 dag kg-1 de DIVMO na avaliação da forragem consumida. As avaliações da qualidade da dieta foram realizadas com as amostras de matéria seca total, sem a separação do milheto do feijão miúdo. Dessa forma, o feijão miúdo deve ter contribuído para os valores elevados de PB e DIVMO das amostras, uma vez que Restle et al. (2002) avaliando o desempenho de novilhos de corte em pastagens com gramíneas de estação quente, na média de cinco períodos de avaliação, obtiveram para o milheto PB de 10,58 dag $\mathrm{kg}^{-1}$ e DIVMO de 54,81 dag $\mathrm{kg}^{-1}$, enquanto no presente estudo estes valores foram de 17 e 68,2 dag $\mathrm{kg}^{-1}$, respectivamente, nos valores de $\mathrm{PB} e$ DIVMO. 
HANISCH, A.L., et al. Desempenho produtivo de vacas...

TABELA 2 - Disponibilidade de forragem total na entrada e na saída dos animais nos piquetes, oferta de MS total (OMS), oferta de lâminas foliares (OLF) de milheto e percentagem de lâminas foliares de milheto no total da matéria seca em quatro períodos de avaliação para o sistema de manejo somente a pasto (MFM).

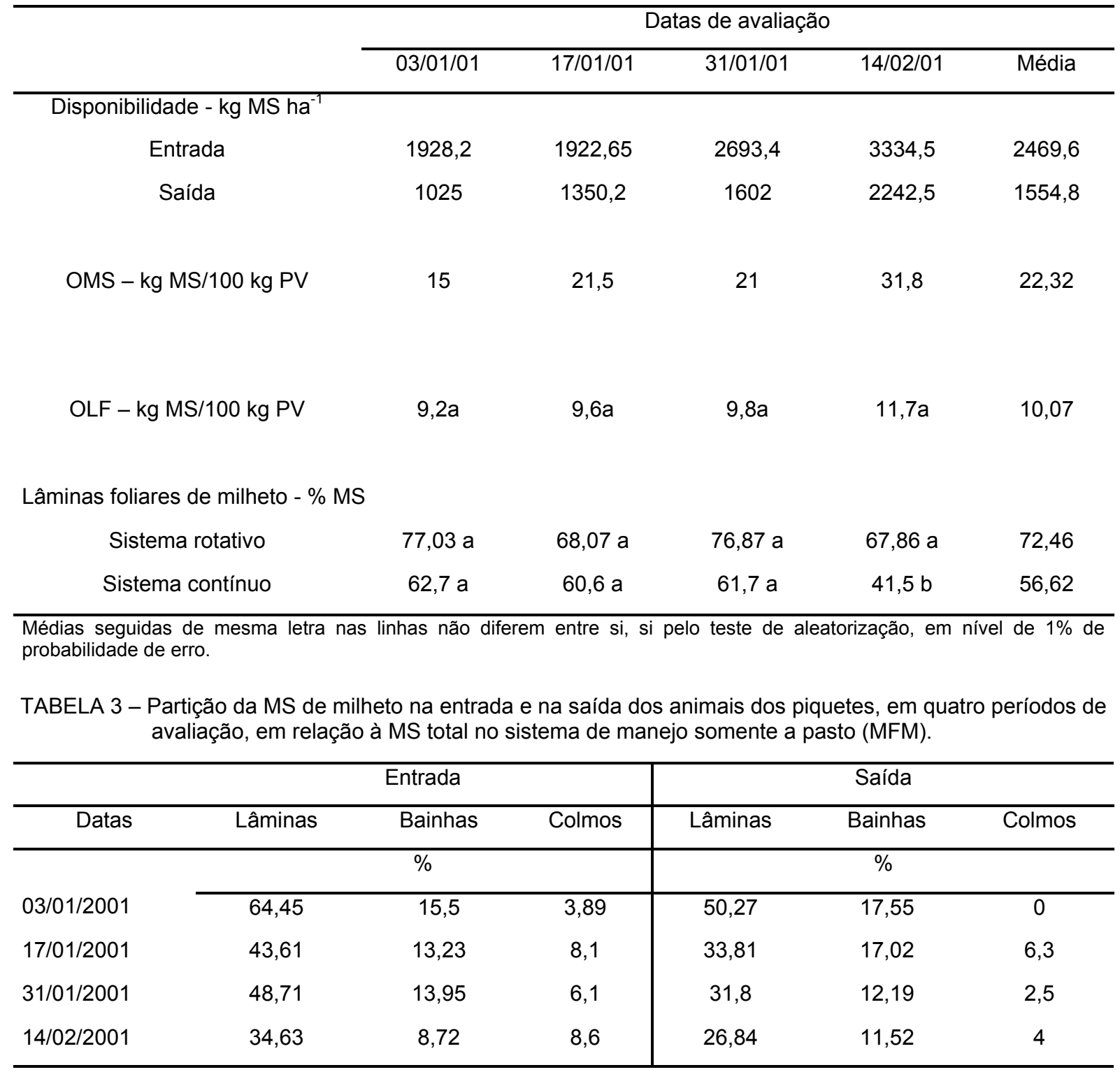

TABELA 4 - Valores de fibra detergente neutro (FDN), proteína bruta (PB) e digestibilidade in vitro da matéria orgânica (DIVMO) em quatro períodos de avaliação nos sistemas somente a pasto (MFM) e média de dois períodos de avaliação no sistema pasto + suplementação (MFM+S)

\begin{tabular}{|c|c|c|c|c|c|}
\hline & \multicolumn{4}{|c|}{ MFM } & \multirow[t]{2}{*}{$\mathrm{MFM}+\mathrm{S}$} \\
\hline & 04/jan & 17/jan & 31/jan & $15 / \mathrm{fev}$ & \\
\hline DIVMO (dag kg $\left.{ }^{-1}\right)$ & 74 & 66 & 70 & 71 & 68,2 \\
\hline PB $\quad\left(\right.$ dag $\left.k^{-1}\right)$ & 16 & 16 & 20 & 14 & 17 \\
\hline FDN $\quad\left(\right.$ dag $\left.\mathrm{kg}^{-1}\right)$ & 67 & 72 & 68 & 67 & 63 \\
\hline
\end{tabular}


HANISCH, A.L., et al. Desempenho produtivo de vacas...

Além disso, sabe-se que a digestibilidade de leguminosas declina de forma muito menos acentuada que a de gramíneas, em um mesmo período (Buxton \& Mertens, 1995), o que sugere a hipótese de que houve uma variação pouco significativa na qualidade do feijão miúdo, dado o curto período do experimento (60 dias), que aliado à prática da roçada no piquete noturno, devem ter contribuído para a manutenção da qualidade total da dieta e nas produtividades obtidas.

$\mathrm{Na}$ Tabela 5 estão apresentados os resultados de ganho de peso dos animais nos três períodos avaliados. Não houve diferença significativa $(P<0,05)$ entre os sistemas de manejo e em ambos, os animais apresentaram variação positiva de peso. Estes resultados diferem dos obtidos por Kolver \& Muller (1998), que observaram perda de peso de $4,5 \%$ do peso vivo em vacas de alto potencial somente em pastagens de azevém e trevo branco, com média de produção diária de 27,6 $\mathrm{kg} \mathrm{vaca}^{-1}$, durante um período de avaliação de 30 dias.

TABELA 5 - Massa viva dos animais nos sistemas somente a pasto (MFM) e pasto + suplementação (MFM+S) no início do experimento, 15 dias após e no final do mesmo.

\begin{tabular}{|c|c|c|c|c|}
\hline \multicolumn{5}{|c|}{ Datas } \\
\hline & 03/01/2001 & $18 / 01 / 2001$ & $14 / 02 / 2001$ & Média \\
\hline & \multicolumn{4}{|c|}{$\mathrm{kg}$ animal ${ }^{-1}$} \\
\hline MFM & 561,30 & 568,30 & 586,50 & $572,03 a$ \\
\hline$M F M+S$ & 591,50 & 620,70 & 622,20 & $611,47 a$ \\
\hline
\end{tabular}

Médias seguidas de mesma letra nas colunas, não diferem entre si, si pelo teste de aleatorização, em nível de 1\% de probabilidade de erro.

\section{CONCLUSÃO}

A suplementação alimentar para vacas de alta produção em pastagem de milheto e feijão miúdo justifica-se devido à maior estabilidade na produção de leite por animal.

\section{AGRADECIMENTOS}

Ao professor Nilton R. Paim da UFRGS por ter-nos propiciado o contato e o apoio junto aos proprietários da Granja VB e aos senhores Virgílio e Ricardo Biesdorff, pela oportunidade proporcionada e pela confiança dispensada ao nosso trabalho. À CAPES pela concessão da bolsa de mestrado e à colega Maria Celina J. Lemos do IAPAR/lbiporã pelo apoio na realização das análises.

\section{REFERÊNCIAS}

1. ANUALPEC. Anuário da pecuária brasileira. São Paulo: Instituto iFNP®, 2005. 285 p.

2. ASSOCIATION OF OFFICIAL ANALYTICAL CHEMISTS - AOAC. Official methods of analysis. 14. ed. Washington, 1984. $1141 \mathrm{p}$.

3. BARCELLOS, A. O. et al. Sustentabilidade da produção animal baseada em pastagens consorciadas e no emprego de leguminosas exclusivas, na forma de banco de proteína, nos trópicos brasileiros. Revista Brasileira de Zootecnia, v. 37, supl. especial, p.51-67, 2008.

4. BUXTON, D. R.; MERTENS, D.R. Quality-related characteristics of forages. In: Forages. 5. ed. Ames: lowa State University Press, 1995 v. 2. p. 83-96.

5. COMISSÃO DE QUIMICA E FERTILIDADE DO SOLO (CQFS-RS/SC). Recomendações de adubação e de calagem para os estados do Rio Grande do Sul e Santa Catarina. 3. ed. Passo Fundo: Sociedade Brasileira de Ciência do Solo/Núcleo Regional Sul/EMBRAPA/CNPT, 1995. 224 p.

6. DELAGARDE, $R$. et al. The effect of nitrogen fertilization level and protein suplementation on herbage intake, feeding behaviour and digestion in grazing dairy cows. Animal Feed, Science and Technology, v. 66, n. 1, p. 165-180, 1997.

7. DERESZ, $\mathrm{F}$ et al. Composição química, digestibilidade e disponibilidade de capim-elefante $\mathrm{cv}$. Napier manejado sob pastejo rotativo. Revista Brasileira de Zootecnia, v. 35, n. 3, p. 863-869, 2006.

8. FAVORETO, M. G. et al. Avaliação nutricional da grama-estrela cv. Africana para vacas leiteiras em condição de pastejo. Revista Brasileira de Zootecnia, v. 37, n. 2, p. 319-327, 2008

9. HAYDOCK, K.P.; SHAW, N.H. The comparative yield method for estimating dry matter yield of pasture. Australian Journal of Experimental Agriculture and Animal Husbandry, v. 15, n. 76, p. 663-670, 1975.

10. HOLMES, C.W.; WILSON, G. F. Produção de leite a pasto. Campinas: Instituto Campineiro de Ensino Agrícola, 1989. $708 \mathrm{p}$.

11. KOLVER, E.S.; MULLER, L.D. Performance and nutrient intake of high producing Holstein cows consuming pasture or a total mixed ration. Journal of Dairy Science, v. 81, n. 5, p.1403-1411, 1998.

12. MARTINS, C.E.N. et al. Variáveis morfogênicas de milheto (Pennisetum americanum) mantido em duas alturas de pastejo. Ciência Rural, v. 35, n. 1, p. 174-180, 2005

13. NASCIMENTO JR. et al. A produção animal em pastagens no Brasil: uso do conhecimento técnico e resultados. In: PRODUÇÃO ANIMAL EM PASTAGENS, 20., 2003, Piracicaba. Anais... Piracicaba: Fundação de Estudos Agrários Luiz de Queiroz, 2003. p. 1-82

14. PEYRAUD, J. L. et al. Relationships between milk production, grass dry matter intake and grass digestion. Rencontres autour des Recherches sur les Ruminants, v. 2, p. 44-67, 2001 
HANISCH, A.L., et al. Desempenho produtivo de vacas...

15. PILLAR, V. da P. MULTIV: Multivariate exploratry analysis and randomization testing. User's guide. Versão 1.3. Porto Alegre, UFRGS, 1997. $34 \mathrm{p}$

16. RESTLE, J. et al. Produção animal em pastagem com gramíneas de estação quente. Revista Brasileira de Zootecnia, v. 31, n. 3, p. 1491-1500, 2002.

17. RIBEIRO FILHO, H.M.N. et al. Suplementação energética para vacas leiteiras pastejando azevém com alta oferta de forragem. Revista Brasileira de Zootecnia, v. 36, n. 6, p. 2152-2158, 2007 (supl.).

18. RIBEIRO FILHO, H.M.N. et al. Consumo de forragem e produção de leite de vacas em pastagem de azevém-anual com duas ofertas de forragem. Revista Brasileira de Zootecnia, v. 38, n. 10, p. 2038-2044, 2009.

19. SANTOS, D. T. et al. Suplementos energéticos para recria de novilhas de corte em pastagens anuais: desempenho animal. Revista Brasileira de Zootecnia, v. 34, n. 1, p. 209-219, 2005.

20. TILLEY, J. M. A.; TERRY, R. A. A two-stage technique of the "in vitro" digestion of forage crop. Journal of the British Grassland Society, v. 18, n. 2, p. 104-111, 1963

21. VAN SOEST, P.J. et al. Methods for dietary fiber, neutral detergent fibers and nonstarch polysaccharides in relation to animal nutrition. Journal of Dairy Science, v. 74, n. 10, p. 3583-3597, 1991.

22. VILELA, D. et al. Desempenho de vacas da raça Holandesa em pastagens de coastcross. Revista Brasileira de Zootecnia, v. 35, n. 2, p. 555-561, 2006.

Recebido em 30/11/2009

Aceito em 06/10/2010 
